\title{
Seismic Response of Tunnel Lining for Shallow-Bias Tunnel with a Small Clear Distance under Wenchuan Earthquake
}

\author{
Yang Hui $\mathbb{D}^{1,2}{ }^{1,2}$ Jiang Xueliang, ${ }^{1,2}$ and Lian Pengyuan ${ }^{1}$ \\ ${ }^{1}$ College of Civil Engineering, Central South University of Forestry and Technology, Changsha, Hunan 410018, China \\ ${ }^{2}$ Rock and Soil Engineering Research Institute, Central South University of Forestry and Technology, Changsha, \\ Hunan 410018, China \\ Correspondence should be addressed to Yang Hui; yanghui-dd@163.com
}

Received 25 December 2017; Revised 10 March 2018; Accepted 1 April 2018; Published 2 May 2018

Academic Editor: Hugo Rodrigues

Copyright (C) 2018 Yang Hui et al. This is an open access article distributed under the Creative Commons Attribution License, which permits unrestricted use, distribution, and reproduction in any medium, provided the original work is properly cited.

In order to study the internal force characteristics of shallow-bias tunnel with a small clear distance in earthquake, a large-scale shaking table slope model test was designed, and the geometric scale was $1: 10$. In the model test, the Wenchuan (WC) seismic wave was used as the excitation wave. Then, the three-dimensional numerical model was established by using MIDAS-NX, and the reliability of the numerical model was verified by comparing the acceleration of the test results. The axial force, bending moment, and shear force of the tunnel cross section and longitudinal direction were calculated by the numerical model under different excitation directions included the horizontal direction $(X)$, the vertical direction $(Z)$, and the horizontal and vertical direction $(X Z)$. The results show the following. (1) The internal force of right arch foot of left hole and the left arch foot of right hole is larger than other part of the tunnels because the distance between the two tunnels is smaller and they interact with each other. (2) The loading direction of single direction loading method is different and the variation trend of tunnel force are different, so the loading direction of seismic wave has a significant influence on the seismic force response of the tunnel. (3) All of the internal force values of tunnel lining under the seismic wave action in bidirection are larger than those in single direction. The value is not a simple superposition of two directions and has some coupling effect. The influence of the vertical seismic wave cannot be ignored in dynamic response research. These results improve the understanding of the rock slope with small spacing tunnel under seismic action.

\section{Introduction}

As an important form of traffic structure, the unsymmetrical loading tunnels usually appear when building roads and railways in hilly, mountainous, sloping areas. Compared with the general tunnel, the bias tunnel has the following characteristics: thin covering rock and soil, asymmetric pressure of surrounding rock, and poor dynamic stability of the whole tunnel. In recent years, earthquakes occur frequently in our country. In Wenchuan earthquake, many tunnels were damaged which including bias tunnels. In all the influence factors of tunnel damage [1], the buried depth is one of the main factors. The tunnel will be constrained greater by surrounding rock with the increase of its depth and will be suffered less damage in earthquake. But in practical engineering, there are many shallow-buried bias tunnels due to topographic conditions, route planning, project cost, and environmental influence. In this condition, the distance between the two tunnels cannot conform to the standard requirements and the pressure on tunnel lining is not even, so many unsymmetrical loading neighborhood tunnels with shallow depth were constructed and, they would be damaged more serious in earthquake.

The dynamic response of tunnels against earthquake has been a subject of intense study after the Wenchuan earthquake and the research, mainly focusing on the experiment and numerical simulation. The shaking table test can simulate the process of earthquake well; it is the most direct and effective method to study the seismic response and failure mechanism of tunnel structure in the laboratory and is one 
of the important methods in earthquake research. In recent years, many scholars have studied the response of the tunnel under earthquake action by model tests and obtained some valuable results [2-13]. The longitudinal distances of $100 \mathrm{~m}$ in the portal section of Galongla tunnel were selected as the prototype to conduct large-scale shaking table test by Shuping et al. [4]; the results showed that the tunnel vibrates synchronously with the surrounding soil and do not show the natural vibration frequency of itself. In order to research the tunnel structure, seismic responses, and the tunnelsurrounding rock interaction, a large-scale 3D shaking table model test was carried out by Hua et al. [5]. Lianjin et al. [6] researched the dynamic response in the portal section of the mountain tunnel with different gradients of upward slope based on large-scale shaking table test. The analysis results showed that an amplified effect of acceleration and displacements of tunnel structures exist at the entrance of the tunnel and there is not much difference in the law of the amplification effect for different gradients of upward slope. In the paper by Feng et al., [7] shaking table tests for seismic response of tunnels were conducted which considering that the tunnel diseases caused by earthquake are different in various depths. In the work of Dong et al., [8] a large-scale shaking table model test is conducted to study the dynamic behavior of entrance slope and its interaction with lining structure of mountain tunnel under earthquake loading. Test results showed that the acceleration response of tunnel entrance slope exhibits obvious amplification effect and surface effect along both vertical and axial directions.

In addition, many scholars also have studied the seismic response of tunnel by numerical simulation. Based on the ABAQUS, Yong [14] studied the effects of tunnel depth, tunnel space, lining stiffness, the properties of surrounding rock, seismic wave incident angle, and seismic intensity on the seismic response of shallow double-hole tunnels. In the paper by Jinsong [15], based on the background of Chongqing Shuangbei tunnel, the three-dimensional numerical model of large section tunnel hole body complex lining was build to research the seismic response calculation and analysis under earthquake. Kunpeng [16] analyzed the seismic dynamic response of unsymmetrically loaded tunnel with the numerical simulation method; it suggested that the unsymmetrical load can increase the entrance length, and the asymmetry of the dynamic response of the tunnel decreased with the increase of the slope soil thickness. The results of numerical calculation are a supplement to the experimental research [16-21].

Although numerous investigation and studies on dynamic response of tunnels have been thoroughly accomplished by many researchers, a few studies have been performed about the internal force of shallow-bias tunnel under seismic actions. In this paper, in order to obtain the internal force of shallow-buried tunnels with small distance under seismic action, a shaking table test was carried out. A three-dimensional numerical model was established by using MIDAS-NX, and the reliability of the numerical model was verified by comparing the acceleration of the test results. This numerical model was used for analyzing the change rule of the internal force of tunnel lining.

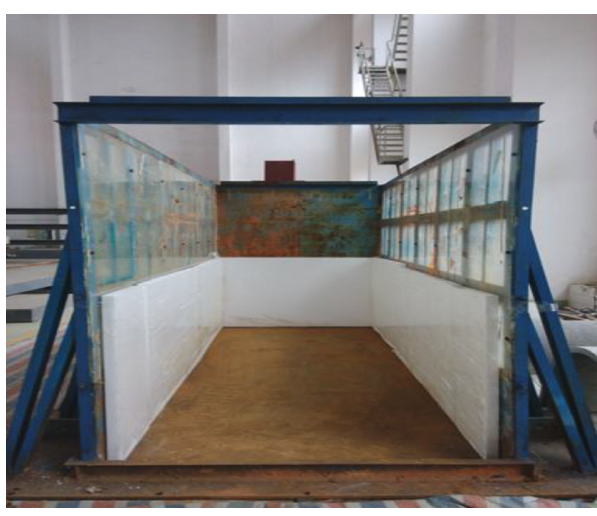

Figure 1: Model box.

\section{Shaking Table Test}

2.1. Test Model. In this test, the rigid model box (Figure 1) was used, and its internal dimensions was $3.5 \mathrm{~m}$ (length) $\times$ $1.5 \mathrm{~m}$ (width) $\times 2.1 \mathrm{~m}$ (height). The perspex plates were installed on both sides of the box. The box was opened at one end for filling material, installing sensor, and observing experimental process.

In order to reducing the reflection of seismic waves and the friction on the contact surface of the model and the model box [22, 23], the polystyrene foam board was pasted on the inner wall of the left and right sides of the model box, and a layer of PVC film was pasted on the polystyrene foam board. The middle sand and crushed stone were used at the bottom of the model box to increase the friction of the cement mortar and the bottom plate and also reduce the relative slip during the vibration.

2.2. Similarity Relation Design. According to the purpose of this test, the geometric similarity ratio, the acceleration similarity ratio, and the density similarity ratio were used as the main control parameters of the model. The table size, maximum weight capacity, boundary effect of the vibration, and the effect of model material were also comprehensively considered. According to similarity theory, the geometric similarity ratio was $1: 10$, the acceleration similarity ratio was $1: 1$, and the density similarity ratio was $1: 1$; other main similarity constants were deduced by similarity theory and dimensional analysis method.

In this test, it was assumed that the tunnel bias was caused by topographic factors and the gradient of rock slope at the top of tunnel was $1: 1.5$. The rock mass from top to bottom were Weak-weathered rock, Poor rock, and Hard rock, respectively. The rock mass was made of cement mortar which physical and mechanical properties was similar. The mixed proportion from top to bottom is $1: 6.30$ : 1.17 (cement: sand: water) of M7.5 mortar, 1:7.25:1.35 (cement:sand:water) of M5 mortar, and 1:5.58:1.04 (cement: sand:water) of M10 mortar, respectively. The tunnel size was designed to be a net height of $60 \mathrm{~cm}$ and a net width of $70 \mathrm{~cm}$; the buried depth was $0.9 \mathrm{~m}$ and thickness of the middle partition wall was $0.4 \mathrm{~m}$ (Figure 2). 


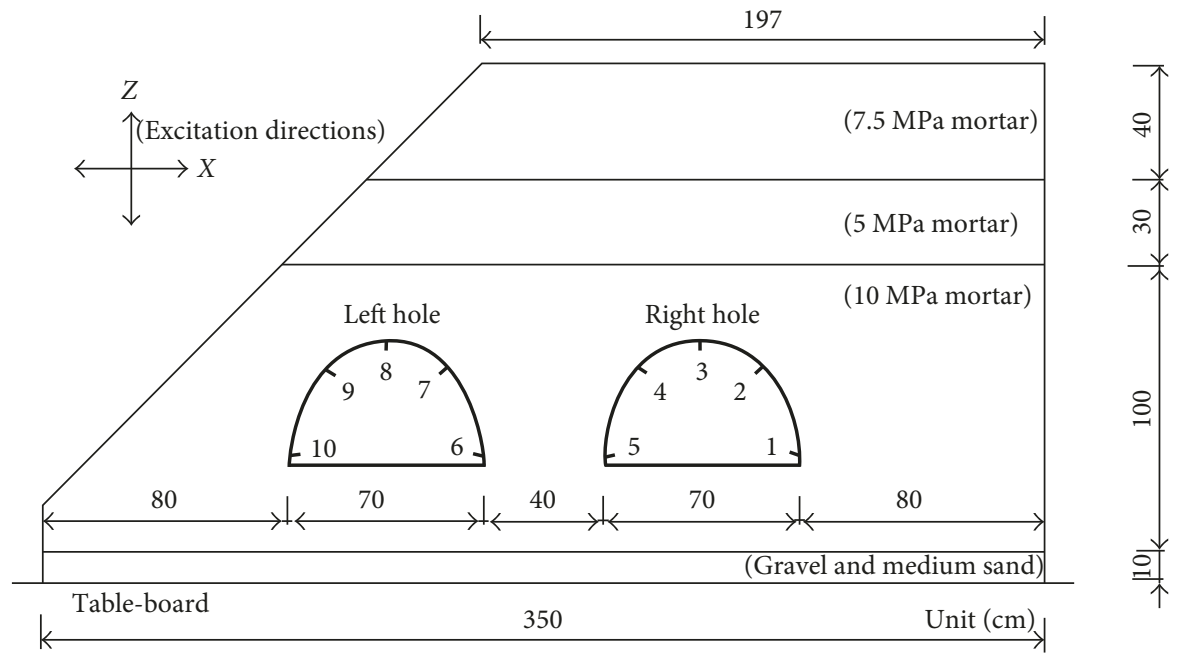

FIgure 2: Slope model and locations of transducers.

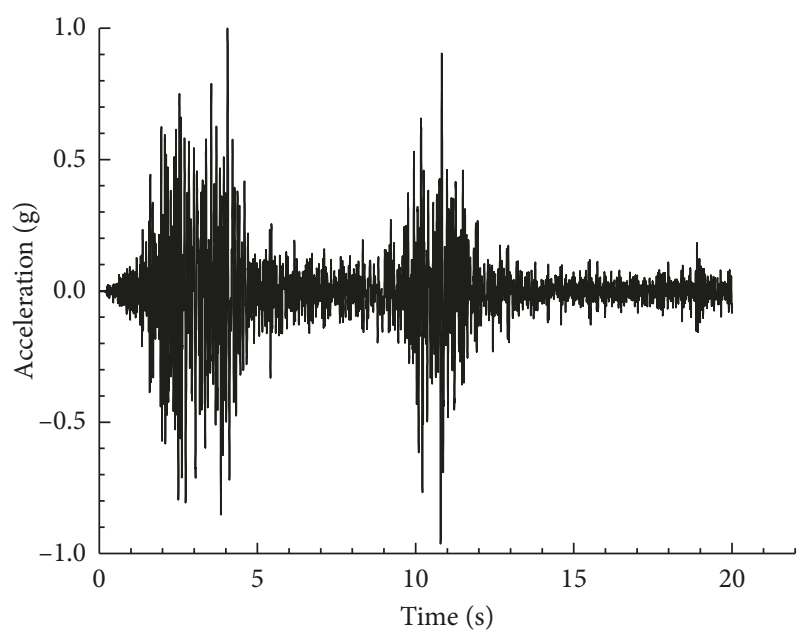

FIgURE 3: Acceleration time-history of Wenchuan seismic wave.

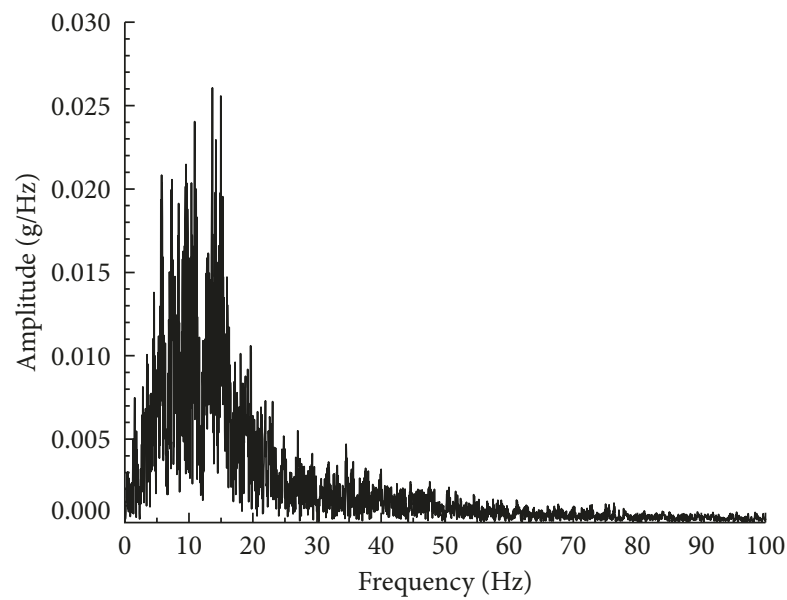

FIgURE 4: Fourier spectrum of Wenchuan seismic wave.

TABLE 1: Loading rule of shaking table test.

\begin{tabular}{lccc}
\hline & & \multicolumn{2}{c}{ Acceleration } \\
Serial number & Working condition & $X$ & $Z$ \\
\hline 1 & & - & - \\
2 & WN-1 & 0.1 & \\
3 & WC-X-1 & & 0.067 \\
4 & WC-Z-1 & 0.1 & 0.067 \\
5 & WC-XZ-1 & - & - \\
6 & WN-2 & 0.2 & - \\
7 & WC-X-2 & - & 0.133 \\
8 & WC-Z-2 & 0.2 & 0.133 \\
9 & WC-XZ-2 & - & - \\
10 & WN-3 & 0.4 & - \\
11 & WC-X-3 & - & 0.267 \\
12 & WC-Z-3 & 0.4 & 0.267 \\
13 & WC-XZ-3 & - & - \\
14 & WN-4 & 0.6 & - \\
15 & WC-X-4 & - & 0.4 \\
16 & WC-Z-4 & 0.6 & 0.4 \\
17 & WC-XZ-4 & - & - \\
\hline
\end{tabular}

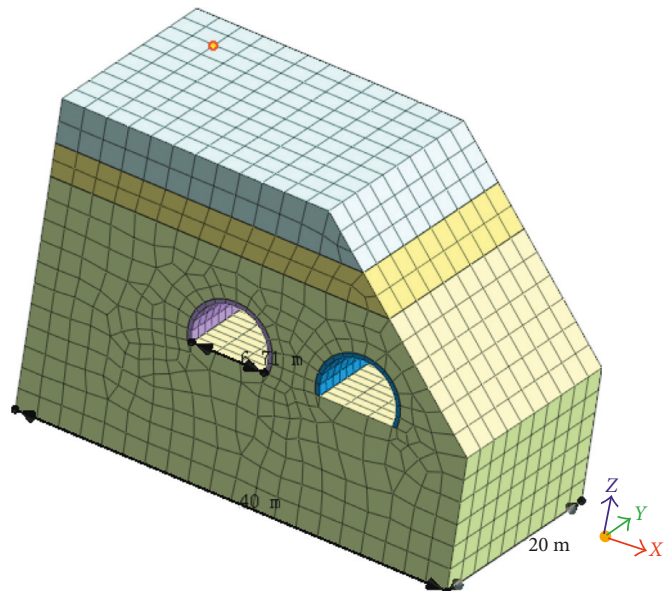

Figure 5: Numerical model. 
The tunnel lining was made of microconcrete which was similar to the physical properties of concrete. Steel bar was simulated with galvanized iron wire. According to the similarity constant, the thickness of tunnel lining was $4 \mathrm{~cm}$. After several times of proportioning test, the optimum tunnel lining material ratio was $1: 6.9: 1.3$ (cement: sand: water). The strength of lining was converted to $5 \mathrm{MPa}$ in accordance with stress similitude ratio.

The data which included acceleration, dynamic strain, and displacement were collected in the test. Its type was $1221 \mathrm{~L}$ 002 , the range was $\pm 20 \mathrm{~m} \cdot \mathrm{s}^{-2}$, and sensitivity was $2000 \mathrm{mv} / \mathrm{g}$. A total of 20 accelerometer sensors, and 30 strain gauges were arranged in the test. The sensors were arranged on the inner wall of each tunnel lining, separately in the arch foot, arch spandrel, arch vault, because they were the key parts of maximum stress and maximum deformation, as shown in Figure 2. The measuring point number is $1-5$ for the right hole and 6-10 for the left hole.

2.3. Seismic Wave Loading. The test was performed in High Speed Railway Construction Technology in Central South University. The vibrating table system consists of one fixed platform and three mobile platforms and these four vibrating tables are in the same line. All of the platforms have six degrees of freedom and the dimensions are $4.0 \mathrm{~m}$ (length) $\times 4.0 \mathrm{~m}$ (width); the working frequency of those test systems is $0.1-50 \mathrm{~Hz}$. The maximum displacement of $X, Y, Z$ direction is $250 \mathrm{~mm}, 250 \mathrm{~mm}, 160 \mathrm{~mm}$, the maximum acceleration in each direction is $\pm 1.0 \mathrm{~g}$, and the maximum seismic vibration velocity is $1000 \mathrm{~mm} / \mathrm{s}$.

The Wenchuan artificial wave was input to simulate earthquake. The main frequency was around $5-25 \mathrm{~Hz}$, and each loading time was $20 \mathrm{~s}$, as shown in Figures 3 and 4. Table 1 shows the loading scheme in the test. Seismic wave was applied with peak accelerations of $0.1 \mathrm{~g}, 0.2 \mathrm{~g}, 0.4 \mathrm{~g}$, and $0.6 \mathrm{~g}$ in $X$ direction and $2 / 3$ of the $X$ direction in $Z$ direction. The white noise input peak wave was applied before seismic wave loading.

\section{Numerical Simulation Analysis}

3.1. Numerical Simulation Model. In this paper, MIDAX/NX software is used to analyze the dynamic response of the tunnel. The main parameters of the numerical model are as follows: the total length is $40 \mathrm{~m}$; the height is $17 \mathrm{~m}$; the length of tunnel is $15 \mathrm{~m}$; and the thickness of tunnel lining is $0.4 \mathrm{~m}$. The surrounding rocks and linings are modeled using threedimensional solid elements, and the total number of units is 75,979 according to the results, as shown in Figure 5. Physical and mechanical parameters of surrounding rocks and linings are shown in Tables 2 and 3. In numerical calculation, the mechanical behavior of elements obeyed elastic-plastic constitutive relation and Mohr-Coulomb yield criterion.

3.2. Verification of Numerical Calculation Model. If MIDAX/NX numerical model is used to analyze the dynamic response of the tunnel, it must be verified that this model can match the experimental model well. So the
TABLE 2: Rock material parameters.

\begin{tabular}{lccc}
\hline Materials & III-fair rock & IV-poor rock & III-hard rock \\
\hline$E(\mathrm{MPa})$ & 6000 & 1300 & 18,900 \\
$\mu$ & 0.3 & 0.25 & 0.3 \\
$\Phi\left(^{\circ}\right)$ & 37 & 30 & 50 \\
$C(\mathrm{kPa})$ & 700 & 200 & 1500 \\
$\gamma\left(\mathrm{kN} \cdot \mathrm{m}^{-3}\right)$ & 23 & 20 & 25 \\
$\sigma_{\mathrm{c}}(\mathrm{MPa})$ & 75 & 50 & 100 \\
Thickness $(\mathrm{m})$ & 5 & 3 & 13 \\
\hline
\end{tabular}

TABLE 3: Lining calculation parameters.

\begin{tabular}{lccc}
\hline$E(\mathrm{GPa})$ & $\mu$ & $\gamma\left(\mathrm{kN} \cdot \mathrm{m}^{-3}\right)$ & Thickness $(\mathrm{m})$ \\
\hline 34.5 & 0.167 & 24 & 0.4 \\
\hline
\end{tabular}

TABLE 4: Comparison of acceleration response peak value in the vertical direction (unit: $\mathrm{m} \cdot \mathrm{s}^{-2}$ ).

\begin{tabular}{lcccc}
\hline \multirow{2}{*}{$\begin{array}{l}\text { Measuring } \\
\text { points }\end{array}$} & $\begin{array}{c}\text { Shaking } \\
\text { table test }\end{array}$ & $\begin{array}{c}\text { Numerical } \\
\text { simulation }\end{array}$ & $\begin{array}{c}\text { Shaking } \\
\text { table test }\end{array}$ & $\begin{array}{c}\text { Numerical } \\
\text { simulation }\end{array}$ \\
\hline 1 & 1.75 & 1.38 & 3.48 & 3.04 \\
2 & 0.88 & 0.42 & 1.72 & 1.51 \\
3 & 1.76 & 1.41 & 3.22 & 2.85 \\
4 & 0.86 & 0.78 & 1.73 & 1.62 \\
5 & 1.69 & 1.38 & 3.21 & 2.54 \\
\hline
\end{tabular}

TABLE 5: Comparison of acceleration response peak value in the horizontal direction (unit: $\mathrm{m} \cdot \mathrm{s}^{-2}$ ).

\begin{tabular}{lcccc}
\hline \multirow{2}{*}{$\begin{array}{l}\text { Measuring } \\
\text { points }\end{array}$} & $\begin{array}{c}\text { Shaking } \\
\text { table test }\end{array}$ & $\begin{array}{c}\text { Numerical } \\
\text { simulation }\end{array}$ & $\begin{array}{c}\text { Shaking } \\
\text { table test }\end{array}$ & $\begin{array}{c}\text { Numerical } \\
\text { simulation }\end{array}$ \\
\hline 1 & 1.95 & 2.11 & 3.45 & 3.79 \\
2 & 1.05 & 1.17 & 1.91 & 1.56 \\
3 & 2.09 & 1.95 & 3.84 & 3.45 \\
4 & 1.96 & 1.68 & 3.7 & 3.3 \\
5 & 1.93 & 1.91 & 3.53 & 3.65 \\
6 & 0.94 & 0.89 & 1.88 & 2.18 \\
7 & 2.1 & 1.85 & 3.85 & 3.71 \\
8 & 1.05 & 1.22 & 1.94 & 1.56 \\
9 & 2.08 & 1.79 & 3.75 & 3.51 \\
10 & 3.12 & 2.76 & 5.75 & 5.29 \\
\hline
\end{tabular}

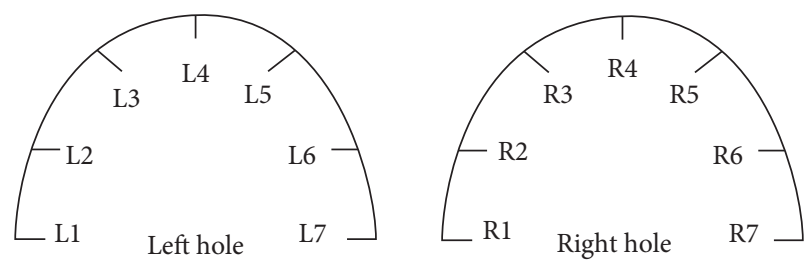

FIGURE 6: Numerical calculation points.

seismic wave input is same as the test. After calculation, the peak acceleration at same position of lining is compared. Comparison of acceleration response peak value under WC-Z seismic wave and WC-X seismic wave is shown in Tables 4 and 5, respectively. 


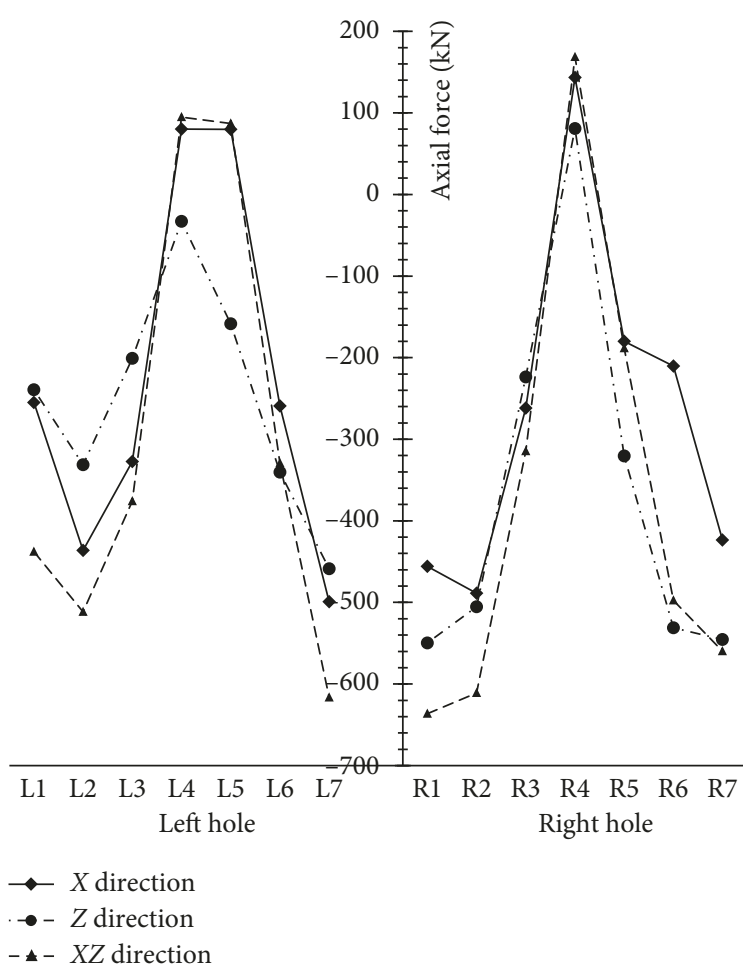

(a)

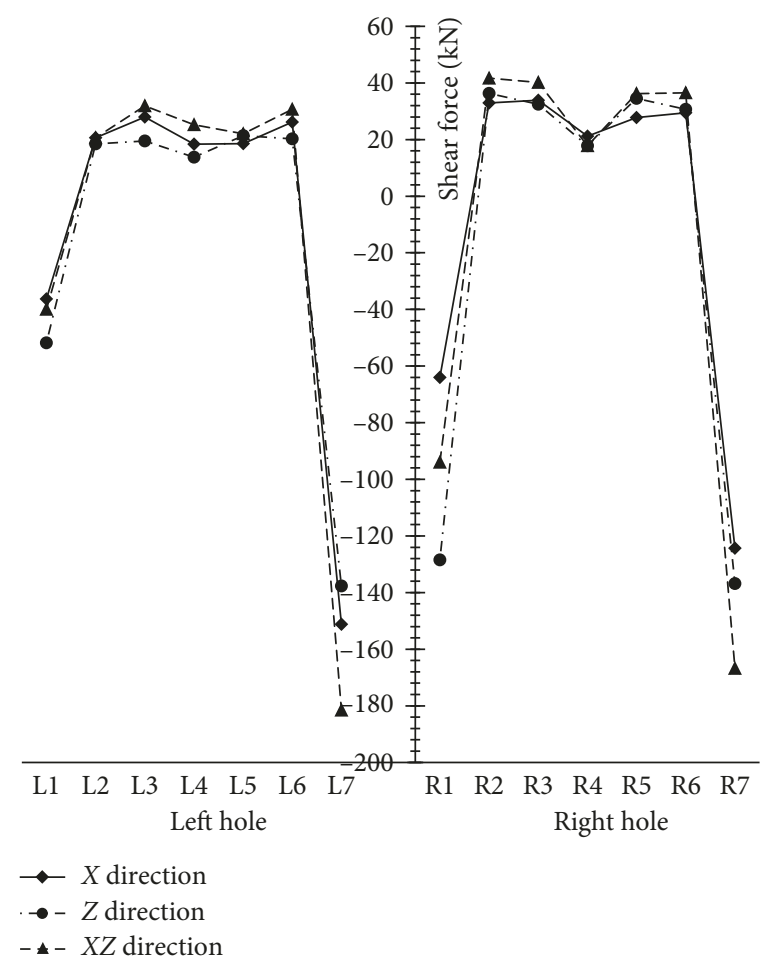

(b)

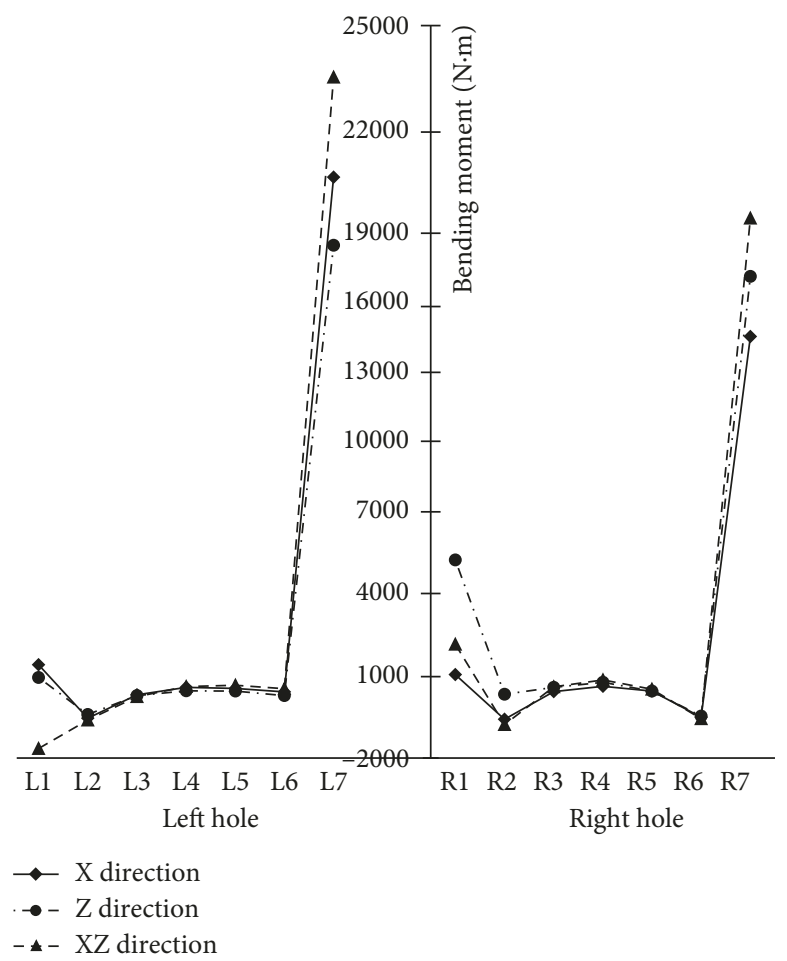

(c)

FIgURE 7: The internal force of lining cross section. (a) Axial force. (b) Shear force. (c) Bending moment.

The analysis shows that the trend of change for peak acceleration is basically the same and the error is within a reasonable range. The numerical model can be used to calculate and analyze the dynamic response of tunnel under many complex conditions when the experiment cannot be simulated in practical.
3.3. Internal Force Analysis of Tunnel Lining Cross Section. According to the test results and numerical analysis, the acceleration and strain reach the maximum at the peak of seismic wave, so the internal force analysis in this paper refers to the tunnel lining at the peak time of the seismic 


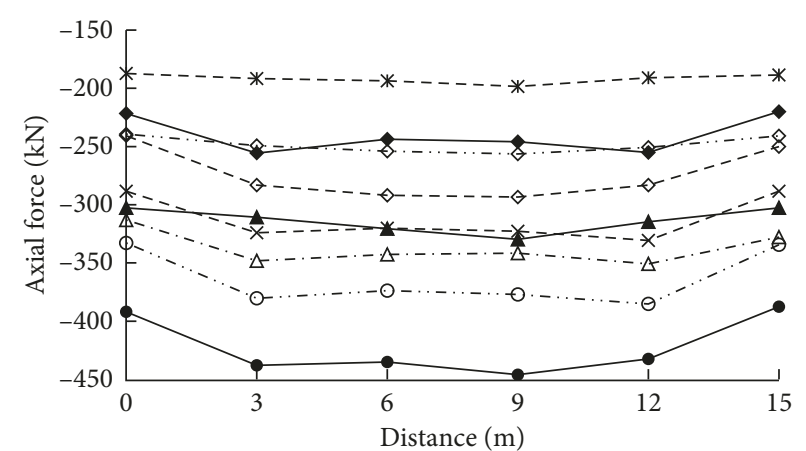

$\rightarrow \mathrm{x}$ direction-L1 $-\diamond-\mathrm{z}$ direction-L1 $\cdot-\Delta-\mathrm{xz}$ direction-L1 $\rightarrow \mathrm{x}$ direction-L2 $-x-\mathrm{z}$ direction-L2 . $-\cdots \mathrm{xz}$ direction-L2 $\rightarrow \mathrm{x}$ direction-L3 $-*-\mathrm{z}$ direction-L3 $. \diamond . . \quad \mathrm{xz}$ direction-L3

(a)

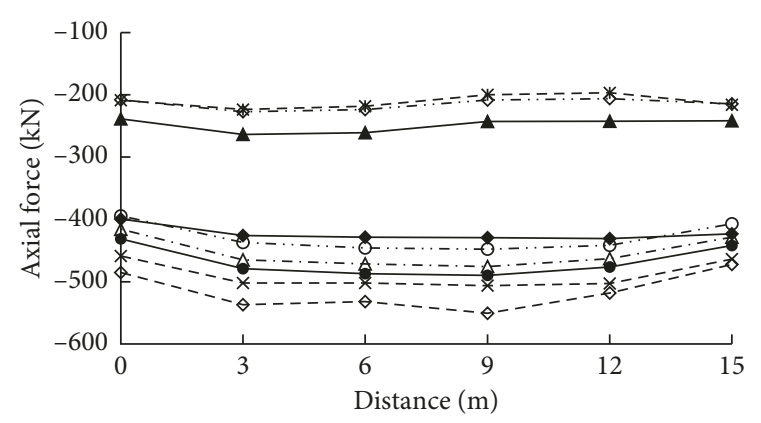

$\rightarrow \quad \mathrm{x}$ direction-R1 $-\diamond-\mathrm{z}$ direction-R1 $-\Delta-\mathrm{xz}$ direction-R1 $\rightarrow \mathrm{x}$ direction-R2 $-*-\mathrm{z}$ direction-R2 $\multimap \ldots$ xz direction-R2 $\leftarrow \mathrm{x}$ direction-R3 $-*-\mathrm{z}$ direction-R3 $\rightarrow$ xz direction-R3

(c)

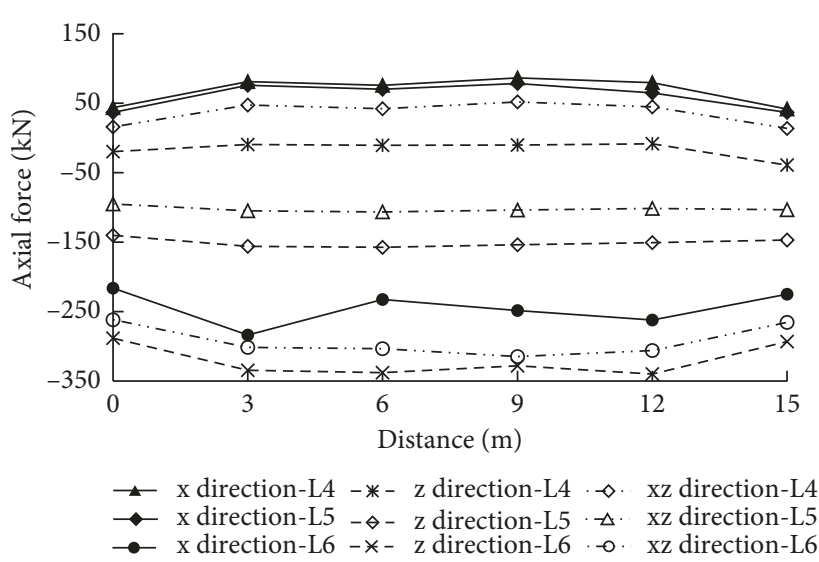

(b)

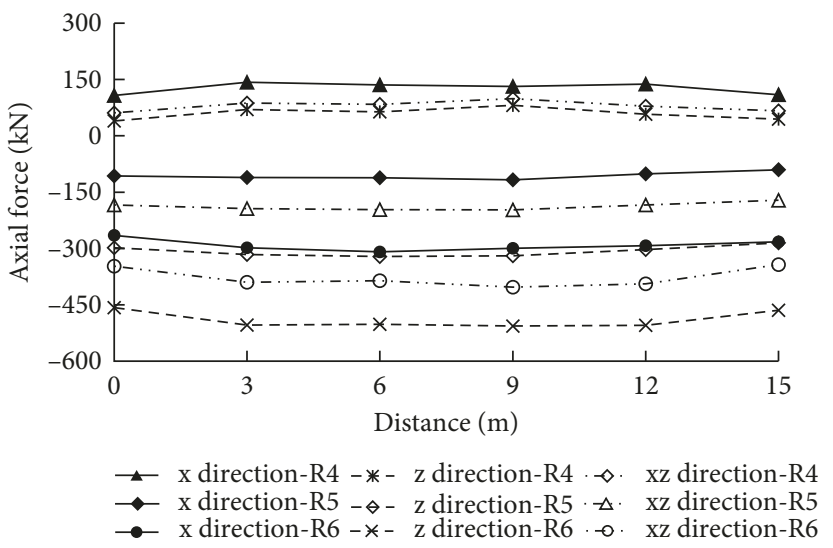

(d)

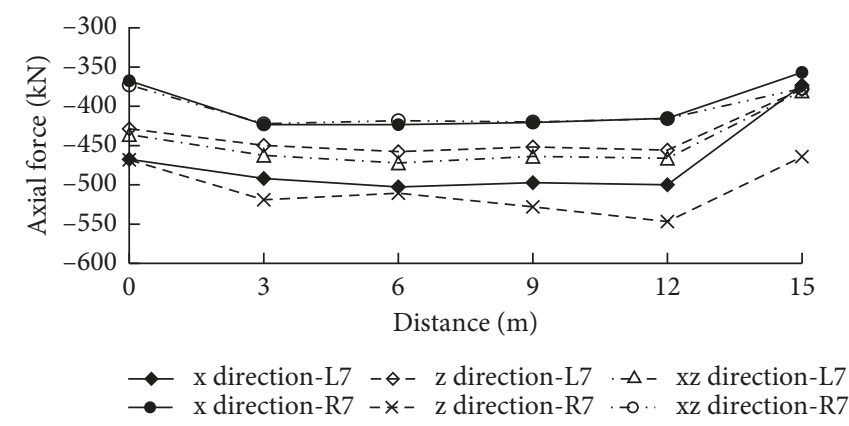

(e)

FIgURE 8: The axial force of tunnel lining along longitudinal direction.

wave. In the following paper, the number of measuring points is $\mathrm{L} 1 \sim \mathrm{L} 7$ in the left hole and $\mathrm{R} 1 \sim \mathrm{R} 7$ in the right hole; the detailed measuring points are shown in Figure 6.

Figure 7, under the action of horizontal seismic waves, to the left tunnel, the vault and right spandrel are tensiled and the others are compressed. The maximum pressure is on the right arch foot and its value is $499.3 \mathrm{kN}$. To the right tunnel, the vault is tensiled and the others are compressed; the maximum pressure is on the left arch waist and its value is $488.8 \mathrm{kN}$. The change of shear force is similar for both linings, the maximum shear force is on the right arch foot, and the value is $-151.2 \mathrm{kN}$ for the left hole and $124.3 \mathrm{kN}$ for the right hole. Sign " \pm " indicates different direction of force. The maximum bending moment is also on the right arch foot; the value is $20,204.6 \mathrm{~N} \cdot \mathrm{m}$ for left hole, and $14,117.8 \mathrm{~N} \cdot \mathrm{m}$ for right hole.

Under the action of vertical seismic waves, the axial force of left tunnel lining is pressure, the maximum pressure is on the right arch foot, and its value is $458.8 \mathrm{kN}$. This is different from the horizontal seismic waves. The change of shear force and bending moment is not obvious; the maximum shear force is $137.7 \mathrm{kN}$ and bending moment is $17,600 \mathrm{~N} \cdot \mathrm{m}$. To the right hole, the axial force and shear force have similar variation trend as the tunnel lining in the horizontal seismic wave action. But the bending moment of left arch waist changes direction and the inside part is changed to the outside part. The maximum is also on right arch foot and the value is $16,410 \mathrm{~N} \cdot \mathrm{m}$. 


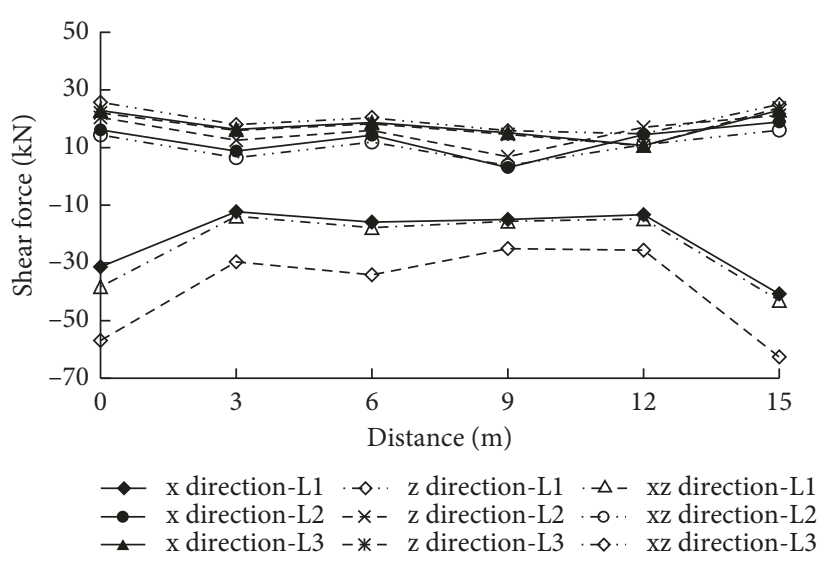

(a)

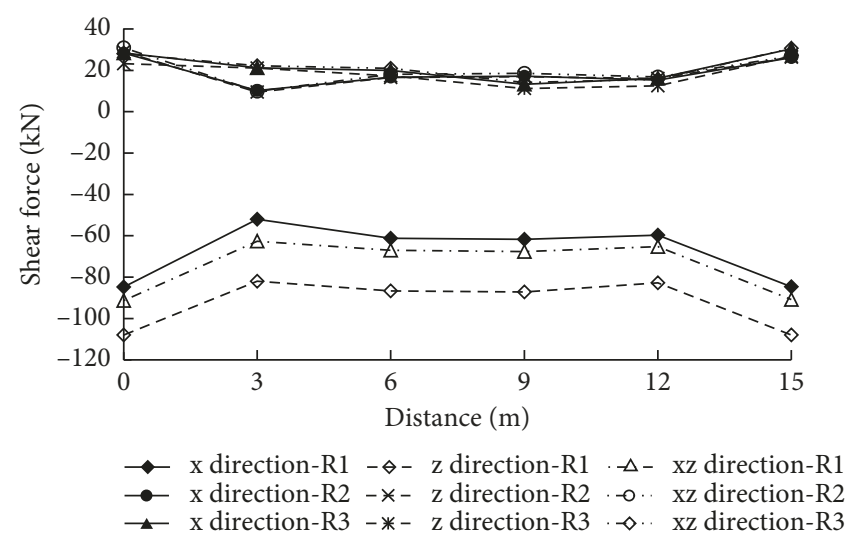

(c)
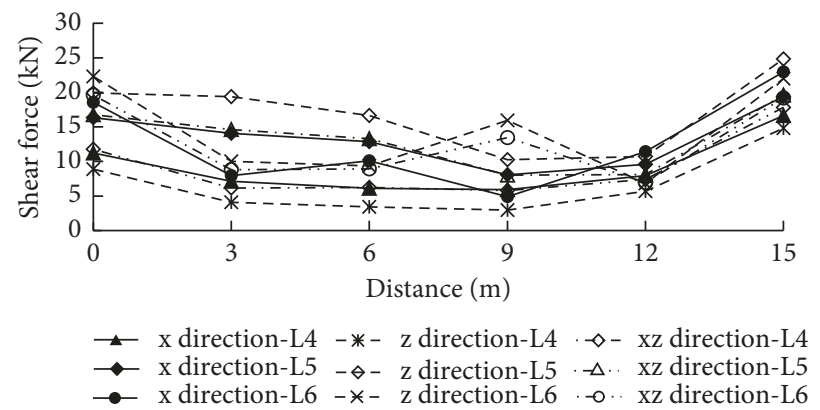

(b)

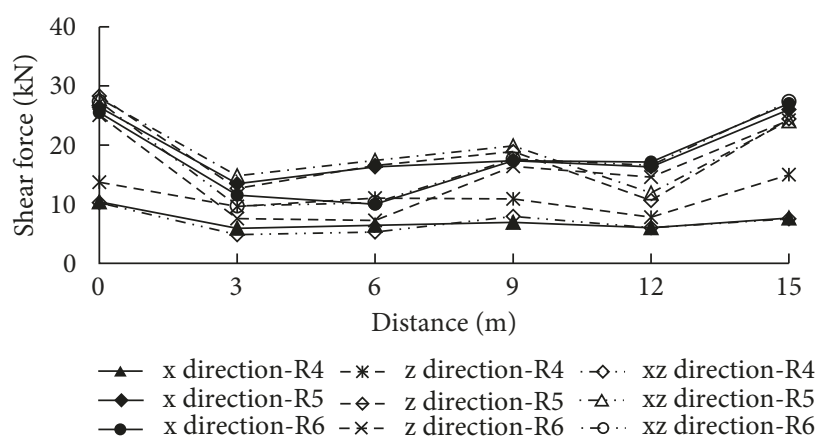

(d)

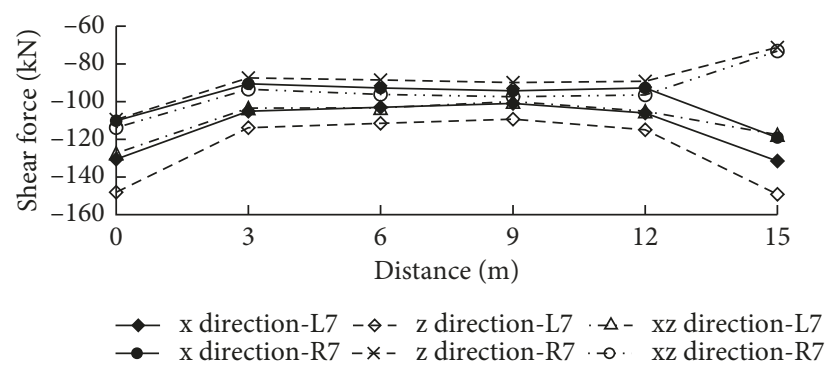

(e)

FIgURE 9: The shear force of tunnel lining along longitudinal direction.

Through the force map, the influence of vertical seismic wave to tunnel lining cannot be ignored; it must be considered in structural design.

The charts also show that all of the internal force values of tunnel lining under the seismic wave action in bidirection ( $X Z$ direction) are larger than those in single direction. But the region which contains arch foot of both linings and the left part near the free surface of left tunnel is the largest part of internal force in three seismic wave input conditions.

The internal force changes significantly in the left side of the left tunnel lining and the arch foot of the right tunnel lining. The reason is that the upper rock layer of the right hole is thick and has good stability, and it is far away from the existing slope and is less affected by the existing slope.
The left hole is close to the existing slope, and the slope has a great influence on the seismic force response of the right tunnel under the earthquake dynamic action.

3.4. Internal Force Changes along the Longitudinal Direction. Under different loading modes, the internal force change along the longitudinal direction is taken as an index to investigate the difference of seismic force response of tunnel, as shown in Figures 8-10.

As shown in Figure 8, the variation of axial force in the same position is smaller along the longitudinal direction of the tunnel. To the left hole, the axial force reaches the maximum at the arch foot and the value is $502.7 \mathrm{kN}$ at $6 \mathrm{~m}$ cross section 


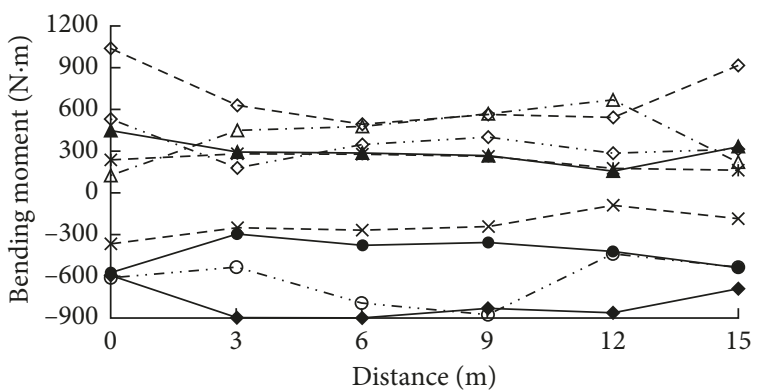

$\neg \mathrm{x}$ direction-L1 $-\diamond-\mathrm{z}$ direction-L1 $\cdot \Delta-\mathrm{xz}$ direction-L1

$\rightarrow \mathrm{x}$ direction-L2 $-\star-\mathrm{z}$ direction-L2 .๑. $\mathrm{xz}$ direction-L2

$\neg-\mathrm{x}$ direction-L3 $-*-\mathrm{z}$ direction-L3 $\diamond \diamond . . \mathrm{xz}$ direction-L3

(a)

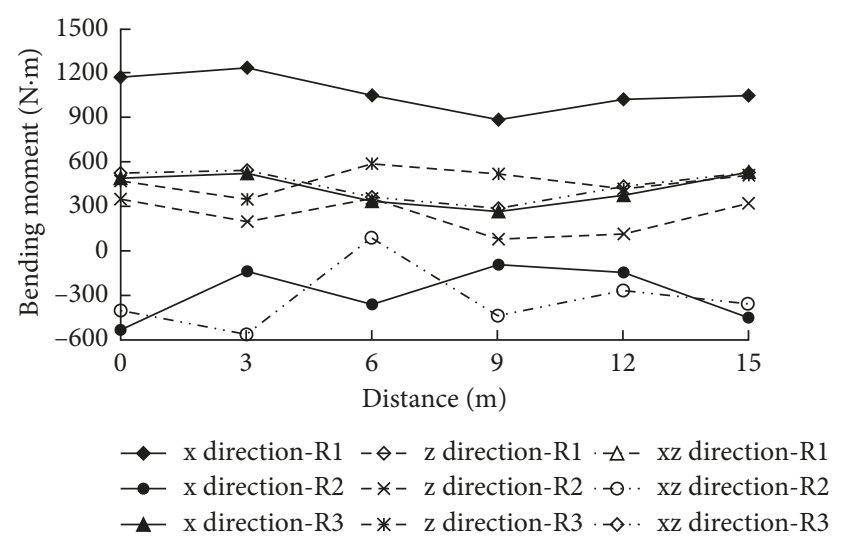

(c)

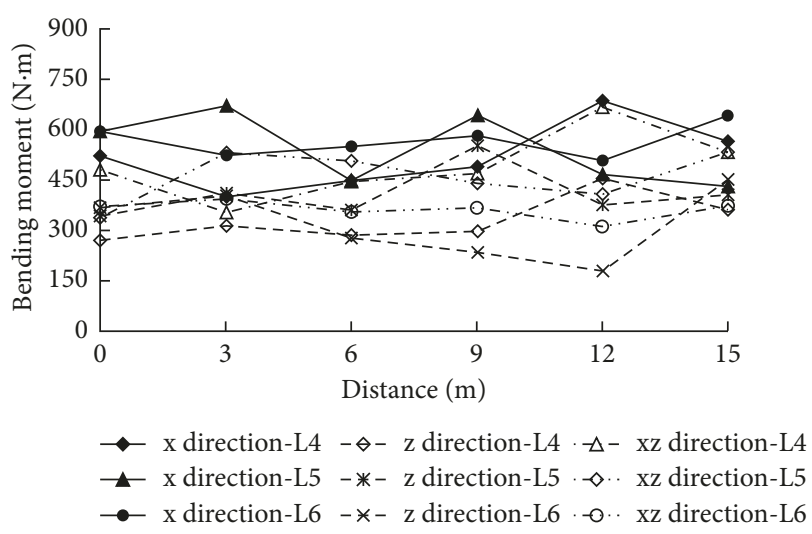

(b)

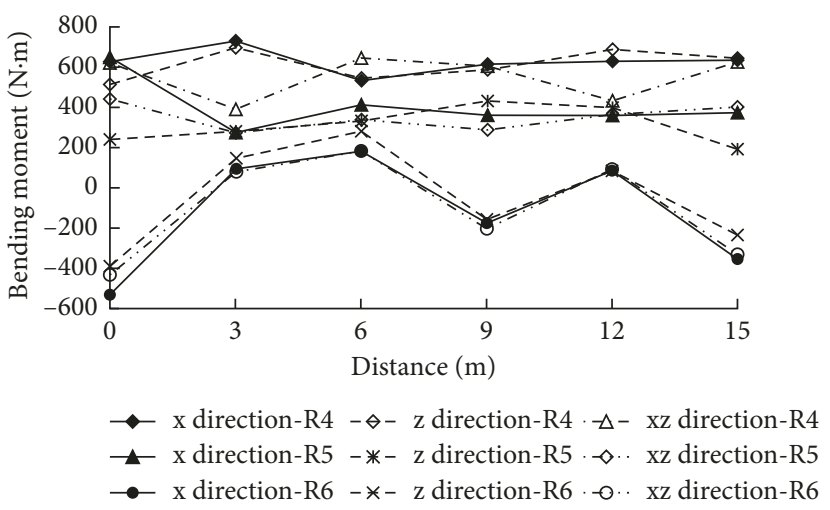

(d)

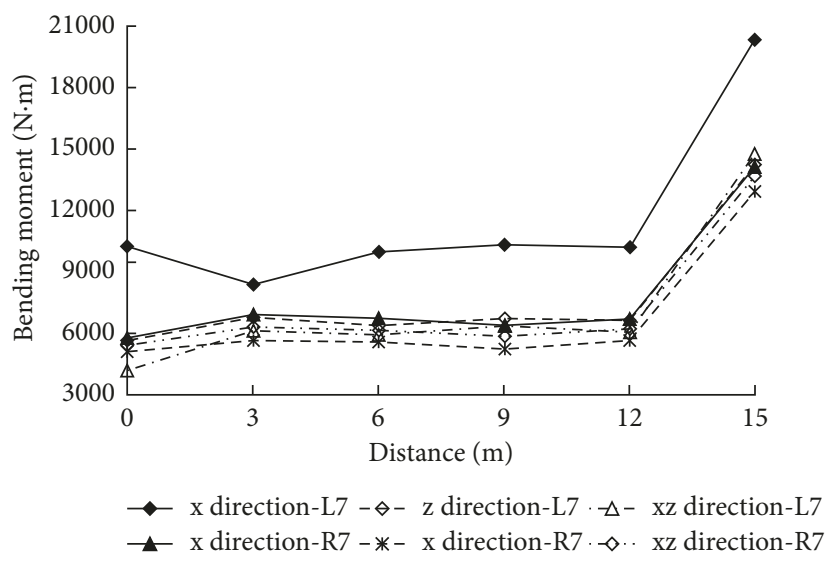

(e)

FIgURE 10: The bending moment of tunnel lining along longitudinal direction.

from the tunnel entrance in the $X$ direction seismic wave. To the right hole, the maximum is left arch foot and the value is $550.6 \mathrm{kN}$ at the $9 \mathrm{~m}$ cross section from the entrance in the $Z$ direction seismic wave. Through comparison, it can be found that the axial force at the middle part of tunnel lining is larger but smaller at the entrance and exit of the tunnel.

As shown in Figure 9, it can be found that the shear force is larger at the entrance and exit of the tunnel than the other part. To the left hole, the shear force reaches the maximum at the right arch foot and the value is $-149 \mathrm{kN}$ at the cross section $15 \mathrm{~m}$ from tunnel entrance in $Z$ direction seismic wave and $-148 \mathrm{kN}$ at the cross section of tunnel entrance. To the right hole, the shear force reaches the maximum at the right arch foot and the value is $-144 \mathrm{kN}$ at the cross section $15 \mathrm{~m}$ from tunnel entrance in the $X Z$ direction seismic wave. From Figure 9, it can be seen that the response of the left hole is more intense than the right hole. The main reason is that in the vertical direction of loading wave, the overlying strata of the right hole is thicker, the action force of the right hole is greater, and the "rise effect" has a significant impact on the shear force response of the right hole. By comparing Figures 8 and 9 , it is suggested that the loading direction of single 
direction loading method is different, the variation trend of tunnel force are different. It shows that the loading direction of seismic wave has a significant influence on the seismic force response of the tunnel.

As shown in Figure 10, the bending moment increases significantly at the arch foot of the tunnel in all loading modes. The maximum is located at the right arch foot of the left hole and the value is $20,339 \mathrm{~N} \cdot \mathrm{m}$ at the cross section of tunnel exit in $x$ direction seismic wave.

By comparing Figures $8-10$, it is summarized as follows:

Because distance between the two tunnels is closer, the internal force of right arch foot of left hole, and the left arch foot of right hole is larger than other part of the tunnels because they interact with each other.

Because of the influence of the existing slope on the internal force response of the tunnel, the variation trend of the internal force of the left and the right hole never show a symmetrical trend.

It can be seen that under the action of bidirectional wave loading, the variation trend of internal force in is more complex, but this trend is similar to $X$ direction wave loading. The reason may be that the response of the vertical direction is stronger than that of the horizontal direction under the action of the bidirectional wave.

\section{Conclusions}

The large-scale shaking table model test was carried out, and the acceleration response of the unsymmetrical loading neighborhood tunnel with shallow depth model in different directions and different acceleration peaks of Whenchuan seismic wave was obtained.

The three-dimensional numerical model of the unsymmetrical loading neighborhood tunnel with shallow depth was established by using MIDAS-NX. The acceleration and internal forces of the tunnels under the same working conditions were obtained, and the reliability of the numerical model was verified by comparing the acceleration of the tunnel lining.

The tunnel lining dynamic response under different loading modes ( $X$ direction, $Z$ direction, and $X Z$ direction) are studied. The axial force, shear force, and bending moment of the tunnel cross section were calculated by the numerical model under the earthquake simulation. The following conclusions are obtained: (1) The internal force of the right arch foot of the left hole and the left arch foot of the right hole is larger than the other part of the tunnels because the distance between the two tunnels is closer and they interact with each other. (2) All of the internal force values of tunnel lining under the seismic wave action in bidirection are larger than those in single direction. The value is not a simple superposition of two directions and has some coupling effect. The influence of the vertical seismic wave cannot be ignored in dynamic response research.

\section{Conflicts of Interest}

The authors declare that they have no conflicts of interest.

\section{Acknowledgments}

The authors are grateful for financial support from the National Natural Science Foundation (NNSF) of China through Grant nos. 51204215 and 51404309.

\section{References}

[1] H. Min, L. Maqun, W. Anhua et al., "The research of tunnel earthquake damage forms and the reasons," Technology and Economy in Area Communications, vol. 57, no. 1, pp. 60-62, 2010.

[2] W. Zhengzheng, G. Bo, and S. Ranxu, "Shaking table tests on entrance anti-seism of double track tunnels," China Journal of Highway and Transport, vol. 22, no. 2, pp. 71-76, 2009.

[3] L. Lin, H. Chuan, G. Ping et al., "Study of shaking table model test for seismic response of portal section of shallow unsymmetrical loading tunnel," Chinese Journal of Rock Mechanics and Engineering, vol. 30, no. 12, pp. 2540-2548, 2011.

[4] J. Shuping, W. Dongliang, and Z. Shengbao, "Large-scale shaking table test for seismic response in portal section of Galongla tunnel," Chinese Journal of Rock Mechanics and Engineering, vol. 30, no. 4, pp. 649-656, 2011.

[5] X. Hua, L. Tianbin, W. Dong et al., "Study of seismic response of mountain tunnels with 3D shaking table model test," Chinese Journal of Rock Mechanics and Engineering, vol. 32, no. 9, pp. 1762-1771, 2013.

[6] T. Lianjin, H. Sen, Z. Xu et al., "Large-scale shaking table test for dynamic response in portal section of mountain tunnel with different gradients of upward slope," Rock and Soil Mechanics, vol. 35, no. 1, pp. 91-98, 2014.

[7] G. Feng, S. Changxin, T. Xukai et al., "Shaking table tests for seismic response of tunnels with different depths," Rock and Soil Mechanics, vol. 36, no. 9, pp. 2517-2523, 2015.

[8] W. Dong, G. Bo, S. Yu-sheng et al., "Shaking table test study of seismic dynamic response of tunnel entrance slope," Rock and Soil Mechanics, vol. 35, no. 7, pp. 1921-1928, 2014.

[9] M. Guowang, Z. Jiamei, and G. Bo, "Seismic responses of fiber reinforced concrete tunnel lining with shaking table test," Chinese Journal of Rock Mechanics and Engineering, vol. 35, no. 6, pp. 1173-1181, 2016.

[10] J. Xueliang, N. Jiayong, Y. Hui et al., "Large-scale shaking table test study on seismic response characteristics of rock slope with small spacing tunnel," Engineering Mechanics, vol. 34, no. 5, pp. 132-147, 2017.

[11] J. Xueliang, L. Pengyuan, Y. Hui et al., "Large-scale shaking table model test study of unsymmetrical loading neighorhood tunnel with shallow depth," Chinese Journal of Applied Mechanics, vol. 34, no. 3, pp. 456-463, 2017.

[12] F. Wang, X. Jiang, and J. Niu, "The large-scale shaking table model of shallow-bias tunnel tith small clear distance," Geotechnical and Geological Engineering, vol. 35, no. 3, pp. 1093-1110, 2017.

[13] H. Min, Study on Seismic Dynamic Response of Shallow Double-Hole Tunnels, M.S. thesis, Southwest Jiaotong University, Chengdu, China, 2009.

[14] W. Yong, Study on Seismic Response Law of Shallow DoubleHole Tunnels, Ph.D. thesis, University of Petroleum, Qingdao, China, 2013.

[15] M. A. Jingson, Dynamic Response Characteristic Analysis on Complex Lining of Tunnel under Earthquake, Ph.D. thesis, Chongqing Jiaotong University, Chongqing, China, 2016.

[16] D. Kunpeng, Study on Seismic Dynamic Response of Unsymmetrically Loaded Tunnel under Strong Earthquakes, Ph.D. thesis, Southwest Jiaotong University, Chengdu, China, 2015. 
[17] S. Tiecheng, W. Zhengzheng, W. Wei et al., "Numerical simulation analysis of seismic dynamic response of tunnel portal section with double holes," Journal of Beijing University of Technology, vol. 39, no. 2, pp. 220-226, 2013.

[18] H. Lin, W. Zhong, and P. Cao, "Three-dimensional rock slope stability analysis considering the surface load distribution," European Journal of Environmental and Civil Engineering, vol. 20, no. 8, pp. 877-898, 2016.

[19] G. Lanzano, E. Bilotta, G. Russo, and F. Silvestri, "Experimental and numerical study on circular tunnels under seismic loading," European Journal of Environmental and Civil Engineering, vol. 19, no. 5, pp. 539-563, 2015.

[20] W. Feifei, J. Xueliang, Y. Hui et al., "Test and numerical simulation for acceleration response laws of a shallow buried small spacing tunnel with asymmetrical pressure," Journal of Vibration and Shock, vol. 36, no. 17, pp. 238-247, 2017.

[21] S.-Y. Lin, H.-H. Hung, J. P. Yang et al., "Seismic analysis of twin tunnels by finite/infinite element approach," International Journal of Geomechanics, vol. 17, no. 9, p. 04017060, 2017.

[22] H. Haohua, The Design and Application Technology on Earthquake Simulation Vibrating Table, Earthquake Press, Beijing, China, 2008.

[23] Z. Yin and L. Xilin, Shaking Table Model Test Method and Technology for Building Structure, Science Press, Beijing, China, 2012. 


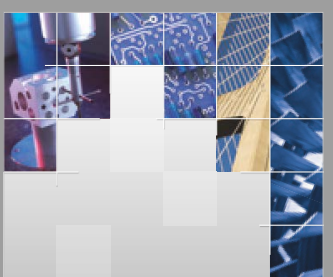

\section{Enfincering}
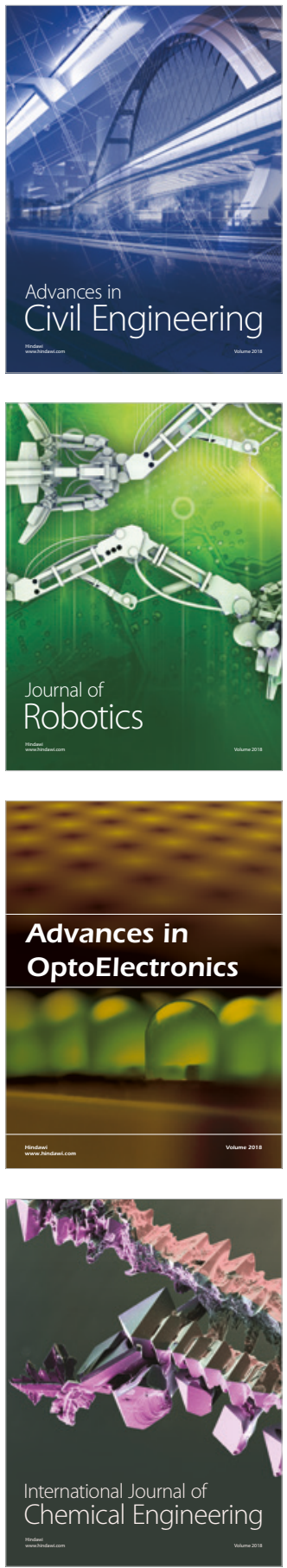

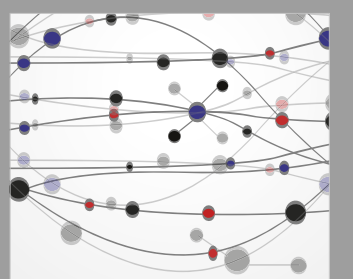

\section{Rotating \\ Machinery}

The Scientific World Journal

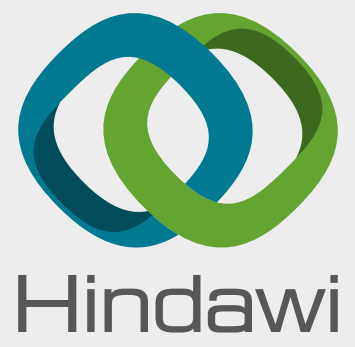

Submit your manuscripts at

www.hindawi.com
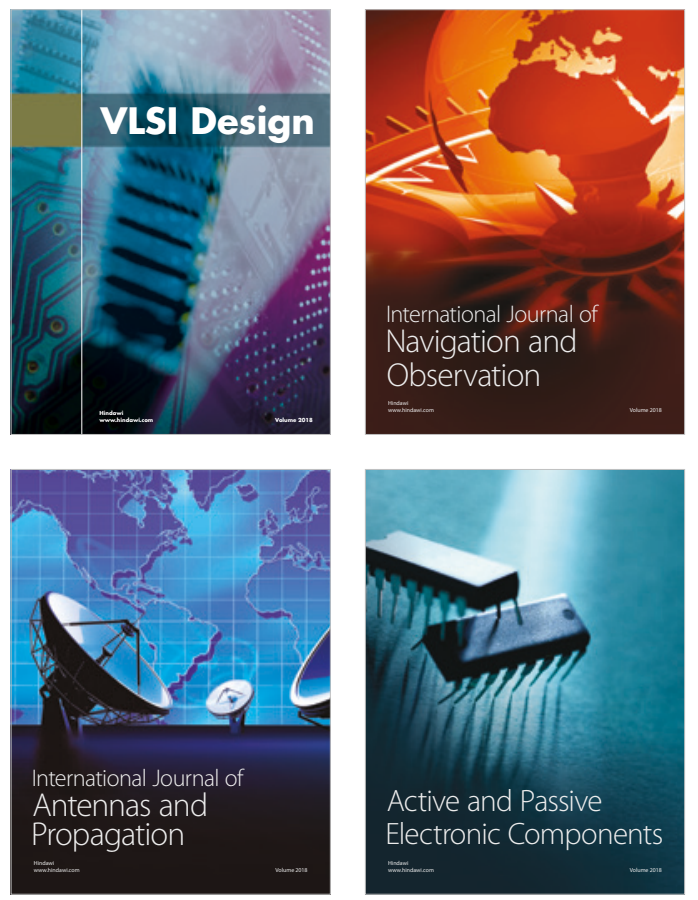
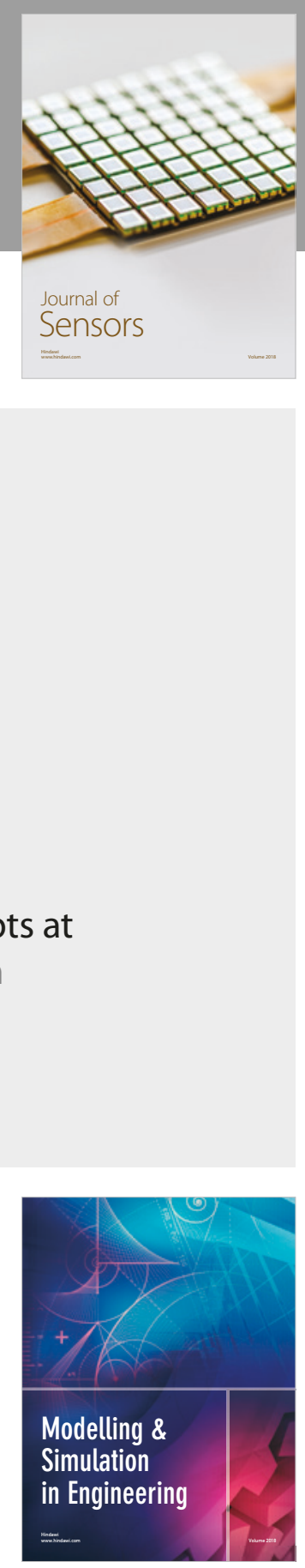

\section{Advances \\ Multimedia}
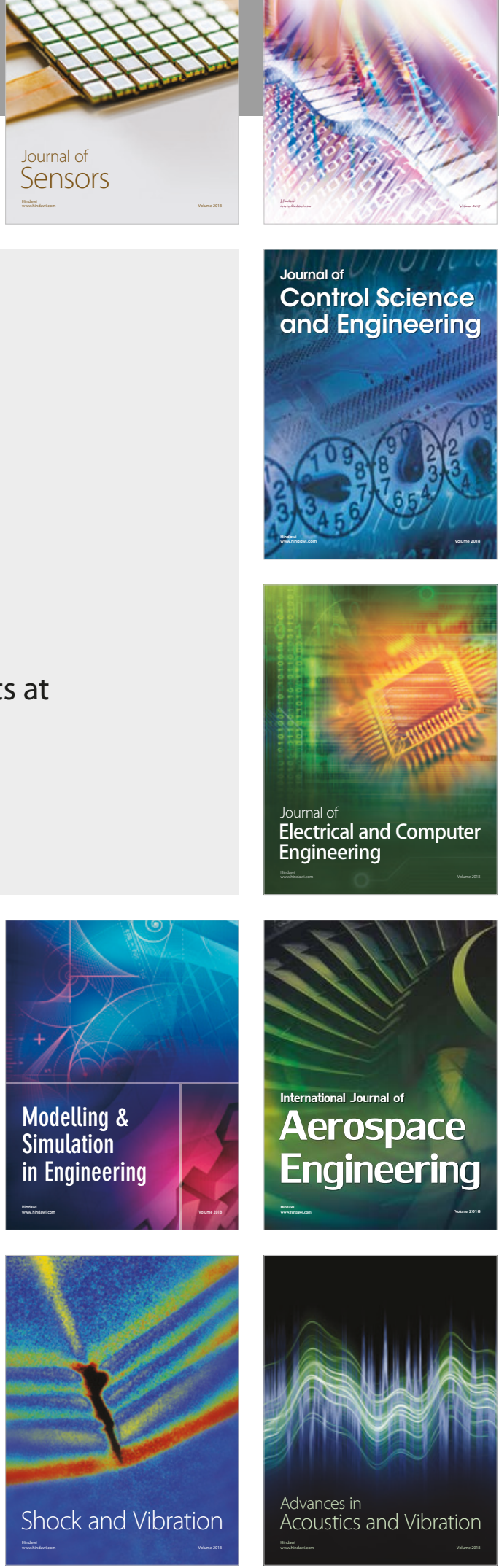